\title{
The Development of the Pars Intermedia and Its Role in the Regulation of Dermal Melanophores in the Larvae of the Amphibian Xenopus laevis
}

\author{
B. M. Lidy Verburg-van Kemenade, Peter H. G. M. Willems, Bruce G. Jenks, \\ AND A. P. VAN OVERBEEKE
}

Department of Zoology, Faculty of Science, Catholic University, Toernooiveld, 6525 ED

Nijmegen, The Netherlands

Accepted April 8, 1983

\begin{abstract}
The ontogenesis of biosynthesis of pro-opiomelanocortin (POMC)-related peptides in the pars intermedia of Xenopus laevis tadpoles was studied. The results were related to the capacity of the animal to adapt to background color through regulation of pigment dispersion in dermal melanophores. Using immunocytochemical techniques with antisera to $\alpha$-melanophore-stimulating hormone ( $\alpha$-MSH), it was revealed that this peptide first appeared at developmental stage $37 / 38$, just prior to the animal's ability to adapt to background. It was shown that pigment dispersion in melanophores between stages 33 and 39 was not dependent on melanotropins of pituitary origin. Using in vitro biosynthetic studies it was possible to follow POMC biosynthetic activity, its processing and the release of peptides from stage 48 onward. Among the newly synthesized peptides observed were a $\gamma_{3}$-MSH-like peptide, des$N$ - $\alpha$-acetyl- $\alpha$-MSH, $\alpha$-MSH, and two endorphin-like peptides. By stage 57 a biosynthetic pattern almost identical to that of the adult pars intermedia had evolved. It was concluded that stage $39 / 40$ is a critical stage in the simultaneous development of a number of the components involved in the neuroendocrine control of background adaptation.
\end{abstract}

Early studies of Atwell (1919) and Swingle (1921) on pigmentation changes in larvae of anurans revealed that the pituitary gland is related to changes in skin color. The full significance of these early observations became clear through the work of Hogben and his colleagues, who showed that a "melanotropic stimulant" from the pars intermedia was directly responsible for the well-known background adaptation (Hogben and Slome, 1931, see also Waring, 1963). Lerner et al. (1954) introduced the name melanophore-stimulating hormone (MSH). Several investigators studying Xenopus laevis established that in this species the pars intermedia produces several different melanotropic substances. Analysis of biosynthetic events in neurointermediate lobes of $X$. laevis showed that the production of melanotropins has the characteristics of a precursor-product relationship
(Loh and Gainer, 1977; Jenks and van Overbeeke, 1980). In vitro and in vivo studies by Martens et al. (1980, 1982a-c, 1983) revealed that in Xenopus the biosynthesis commences with the production of a prohormone, pro-opiomelanocortin (POMC) which is subsequently processed to yield three melanotropic peptides, namely, $\alpha-\mathrm{MSH}$, des- $N$ - $\alpha$-acetyl- $\alpha-\mathrm{MSH}$, and a $\gamma_{3}-\mathrm{MSH}$-like peptide, as well as several other peptides, including two forms of a corticotropin-like intermediate peptide (CLIP) and two peptides structurally related to the endogenous opiate $\beta$-endorphin. Analysis of release showed spontaneous secretion of all these peptides with the exception of des- $N$ - $\alpha$-acetyl- $\alpha$-MSH which was acetylated to form $\alpha$-MSH during the release process (Martens et al., 1981a). Dopamine was shown to inhibit release of all secretory peptides (Martens et 
al., 1981b). This latter observation is consistent with the concept that release of peptides from the pars intermedia of Xenopus is under inhibitory control through a dopaminergic system (Terlou et al., 1974; Jenks, 1977).

The apparent diversity of the terminal products of the pars intermedia prompted questions concerning the ontogenetic development of this system. We report the results of an investigation concerning the biosynthetic activity in the pars intermedia and the release of its products during larval development of $X$. laevis. As pituitary glands of larvae before stage $47 / 48$ could not be isolated for biochemical analysis, pertinent aspects of very early development were studied with morphological and immunocytochemical methods. In addition, the functioning of the pars intermedia in young tadpoles, prior to the development of their capacity to adapt to background, was investigated.

\section{MATERIALS AND METHODS}

Animals. Xenopus laevis tadpoles were bred and reared in the aquarium facility of the Department of Zoology, Catholic University, Nijmegen, The Netherlands. Spawning was induced by injection of Pregnyl (Urganon, Oss, The Netherlands) into the dorsal lymph sac. The male was given a daily injection of 300 I.U. for two consecutive days, while the female was given a single injection of 600 I.U. (on the second day only). Tadpoles were kept at $22^{\circ}$ under constant illumination on black or white backgrounds. From stage 46 onward, the tadpoles were fed powdered urticaceae leaves (J. Hooy B.V., Limmen, The Netherlands) to which was added $1 \% \mathrm{w} / \mathrm{w}$ each of milk powder and yeast. For the first 3 days after metamorphosis animals were fed tubifex and thereafter they received Amficon (Trouw, Putten, The Netherlands). The developmental stages of the tadpoles were determined using the standard table of Nieuwkoop and Faber (1967). The degree of pigment dispersion in the dermal melanophores was determined according to the index of Hogben and Slome (1931).

Histological and immunocytochemical techniques. To investigate the development and differentiation of the pituitary gland, tadpoles of various stages as well as postmetamorphic animals from both white and black backgrounds were selected. Tissue was fixed in
Bouin's fluid, embedded in Paraplast, and sectioned at 5 or $7 \mu \mathrm{m}$. For morphological study, sections were stained using Geidies' trichrome procedure. Immunocytochemical identification of cell types was achieved using the peroxidase-anti-peroxidase method of Sternberger (1979), using 4-Cl-naphthol as an oxygen acceptor. In these studies antisera to $\alpha$ MSH, $\beta$-endorphin, ACTH, and $\gamma-\mathrm{MSH}$ were used. The anti- $\beta$-endorphin was a gift from $H$. Vaudry (Rouen, France) and the anti- $\gamma-\mathrm{MSH}$ was a gift from P. Lowry (London). The anti- $\alpha-\mathrm{MSH}$ and anti-ACTH were raised against synthetic $\alpha$-MSH (Peninsula) and $\mathrm{ACTH}_{1-24}$ (Organon), respectively; both antigens were first conjugated with glutaraldehyde to bovine serum albumin (BSA). The antiserum to $\alpha$-MSH showed minimal cross-reactivity $(<0.01 \%)$ with $\mathrm{ACTH}_{4-10}$, reacted weakly $(<2 \%)$ with $\mathrm{ACTH}_{1-10}$ and porcine $\mathrm{ACTH}_{1-39}$, and showed a cross-reactivity of $\sim 15 \%$ with des- $N$ - $\alpha$-acetyl- $\alpha$-MSH. Specificity of immunohistochemical binding of anti- $\alpha-\mathrm{MSH}$ and anti-ACTH was shown by incubation of the antiserum with an excess of the appropriate hormone. Sensitivity was tested by staining with serially diluted sampies of the primary antibody.

Regulation of melanophores during early larval development. To assess whether in larvae younger than stage 39 pigment dispersion in the melanophores is under pituitary control, we had hoped to follow the effect of hypophysectomy. Since at these young stages this operation was impossible, the decapitation procedure of Bagnara (1963) was employed. Approximately 200 animals at stage $25-27(30 \mathrm{hr}$ of development) from three different clutches were used. Half of these animals were used as controls and the remainder were decapitated just behind the gill primordium. At this stage they had not yet developed melanophores. All animals were placed on black backgrounds. The morphogenetic development of the control and decapitated animals was then followed for the next 3 days using the criteria of Nieuwkoop and Faber (1967). Melanophore formation and the degree of melanin dispersion was recorded for each developmental stage.

Analysis of biosynthesis in larval pituitary glands. Tadpoles were killed by severing the spinal cord, and two lateral cuts were made through the skull such that the tissue containing the upper jaw and brain could be removed and placed under a dissecting microscope to view the ventral surface. Using fine, electrolytically sharpened needles, the upper jaw bone was cut down the midline and spread apart, exposing the brain. A drop of frog Ringer's solution was applied and the pituitary gland was lifted out with a pair of fine tweezers and transferred to an incubation vial. The glands were kept in $100 \mu \mathrm{l}$ carbogen-aerated $\left(\mathrm{O}_{2}: \mathrm{CO}_{2} 95 \%: 5 \%\right)$ incubation medium (112 $\mathrm{mM} \mathrm{NaCl}, 2 \mathrm{mM} \mathrm{KCl,} 2 \mathrm{~m} M$ $\mathrm{CaCl}_{2}, 15 \mathrm{~m} M$ Hepes, pH $7.38,0.3 \mathrm{mg} / \mathrm{ml}$ BSA. $2 \mathrm{mg} /$ $\mathrm{ml}$ glucose) for $30-60 \mathrm{~min}$ at $22^{\circ}$. The biosynthetic 
studies were conducted with 10-25 larval pituitary glands per incubation. For analysis of newly synthesized products in the adult, a single neurointermediate lobe was used. Lobes were given a pulse incubation for $2 \mathrm{hr}$ in $30 \mu \mathrm{l}$ of incubation medium containing 20 $\mu \mathrm{Ci} \mathrm{L}-\left[4,5-{ }^{3} \mathrm{H}\right] \mathrm{lysine}(90 \mathrm{Ci} / \mathrm{mmol}$, Amersham, United

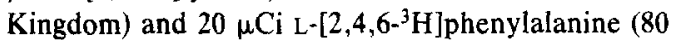
$\mathrm{Ci} / \mathrm{mmol}$, Amersham) in a Dubnoff metabolic shaker at $22^{\circ}$. After the pulse incubation the medium was carefully aspirated and the lobes were rinsed three times in $50 \mu$ l chase medium. A 2-hr chase incubation was performed in $100 \mu 1$ medium containing $1 \mathrm{mM}$ each of $\mathrm{L}$-lysine and $\mathrm{L}$-phenylalanine (Calbiochem, San Diego, Calif.). The lobes were homogenized in 500 $\mu l 0.1 \mathrm{M} \mathrm{HCl}$, the homogenate was centrifuged for 5 $\min$ at $10,000 \mathrm{~g}$, and the supernatant was submitted to high-performance liquid chromatography (HPLC). The chase medium was acidified with $500 \mu \mathrm{l} 0.1 \mathrm{M}$ $\mathrm{HCl}$ and centrifuged prior to HPLC analysis.

HPLC separations of peptides were carried out using a Spherisorb 10 ODS column (Chrompack 250 $\times 4.6 \mathrm{~mm}$ i.d.) with a flow rate of $2 \mathrm{ml} / \mathrm{min}$. The elution gradient consisted of $0.5 M$ formic acid-0.14 $M$ pyridine (pII 3.0, solvent A) and 1-propanol (solvent B). One-milliliter fractions were collected. Four milliliters of emulsifier scintillator 299 (Packard, Brussels, Belgium) was added and the radioactivity in cach vial was determined with a liquid scintillation analyzer. Further details concerning the chromatographic procedures can be found in Martens et al. $(1980,1982 \mathrm{a})$.

\section{RESULTS}

Tadpoles developed their first melanophores during stages 33/34 (Fig. 1). The pigment in the melanophores remained dispersed until the animals started to respond to background, around stages 39 to 41 . At this time the pigment in the melanophores of animals kept on a black background remained dispersed, while in animals maintained on white background an aggregation of this pigment occurred. Occasionally, black-adapted tadpoles of stages 39 to 41 would show temporary aggregation of pigment. Exposing tadpoles younger than stage $39 / 40$ to the dopamine receptor agonist apomorphine (Brocacef B.V., Maarssen, The Netherlands), by adding it to the water (final concentration, $10^{-6} M$ ), did not affect their melanophore index. The same experiment conducted on animals older than stage $39 / 40$ showed that apo- morphine treatment led to aggregation of pigment (Fig. 1). Control experiments using isolated larval tails showed that the melanophores themselves were not sensitive to apomorphine.

\section{Development of the Adenohypophyseal Primordium}

The early primordium of the adenohypophysis, developing from the stomodeal hypophyseal anlage, was distinguishable at about stage 21 . It grew in a caudal direction. By stage 31 to 33 it detached from the ectoderm, reaching its final position, just underneath the infundibulum, at about stage 39/40 (Fig. 1). In early stages, numerous cells of the pituitary gland contained yolk granules which had disappeared by stage $38 / 39$.

\section{Immunocytochemical Investigation of POMC-Related Peptides}

Occasionally, a slight positive reaction to anti- $\alpha-$ MSH was found in the pituitary gland of animals at stage $37 / 38$. By stage 39 , slightly before the animals were capable of background adaptation, a positive reaction was seen in all animals. The intensity of this reaction increased between stages 39 and 43 (Fig. 2A). The positive reaction could be found in two distinct regions, one representing the future pars intermedia, the other the anterior part of the developing pars distalis. At stage 39 these two cell groups bound both anti- $\alpha-\mathrm{MSH}$ and antiACTH antisera and, from stage 41 onward, they also showed $\gamma$-MSH-like and $\beta$-endorphin-like immunoreactivity. Binding of antiACTH was strongest in the cells of the pars anterior; anti- $\alpha$-MSH and anti- $\beta$-endorphin were bound most strongly by the pars intermedia cells (Fig. 2C). In the pars intermedia at stage 45 and 46 , affinity for anti$\alpha$-MSH was always stronger in cells of black-adapted tadpoles than in those of white-adapted ones (Fig. 2B). 

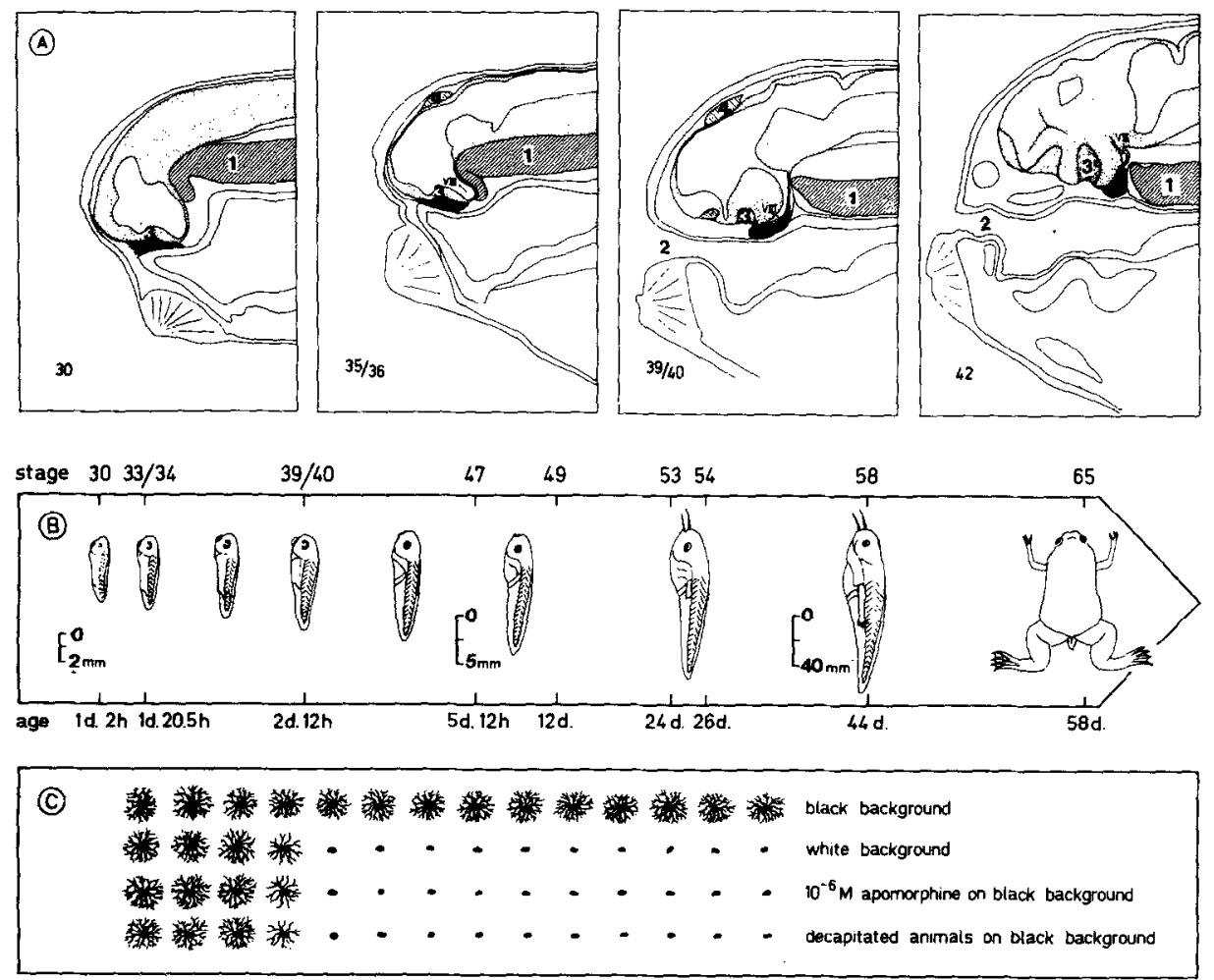

FIG. 1. (A) Morphological development of the pituitary gland in $X$. laevis. Stages indicated in the lower left of each diagram were determined by the criteria of Nieuwkoop and Faber (1967). The migrating adenohypophysial primordium is indicated in black. 1, notochord; 2, mouth opening; 3 , optic chiasma; 4, pineal gland; VIII, infundibular recess of the third ventricle. (B) Schematic diagram showing the development of $X$. laevis larvae as a function of time. (C) Melanophore appearance under various experimental conditions in relation to the time axis given in $\mathrm{B}$. In all cases the first melanophores appeared in stage 33/34.

\section{Regulation of Melanophores during Early Larval Development}

Over $80 \%$ of the decapitated animals survived the operation. The wounds quickly healed and, judging from the features that are used as criteria for development by Nieuwkoop and Faber (1967) (e.g., tail development, number of somites, gut development, and melanophore differentiation), the operation did not interfere with the normal development of these tadpoles. Both the rate of differentiation and the features of the differentiated tissue were the same in the decapitated animals and the controls. In both groups, melanophores appeared at stage $33 / 34$ and the pigment within the melanophores quickly dispersed and remained in the fully dispersed state until stage 39 (Fig. 3). Between stages 39 and 41 all of the pigment in the melanophores of the decapitated animals became punctate while that of the control animals remained dispersed. To determine whether the melanophores of the decapitated animals werc sensitive to MSH, in vitro experiments were performed on isolated tails of these animals after pigment aggregation in stage 41. $\alpha-\mathrm{MSH}$ (a gift from Organon B.V.) at a concentration of $1 \mu \mathrm{g} / \mathrm{ml}$ in the aquarium water caused complete pigment dispersion in the melanophores.

\section{Analysis of Biosynthesis in Larval Pituitary Glands}

Separation of intact larval neurointermediate lobes for the pulse-chase experi- 

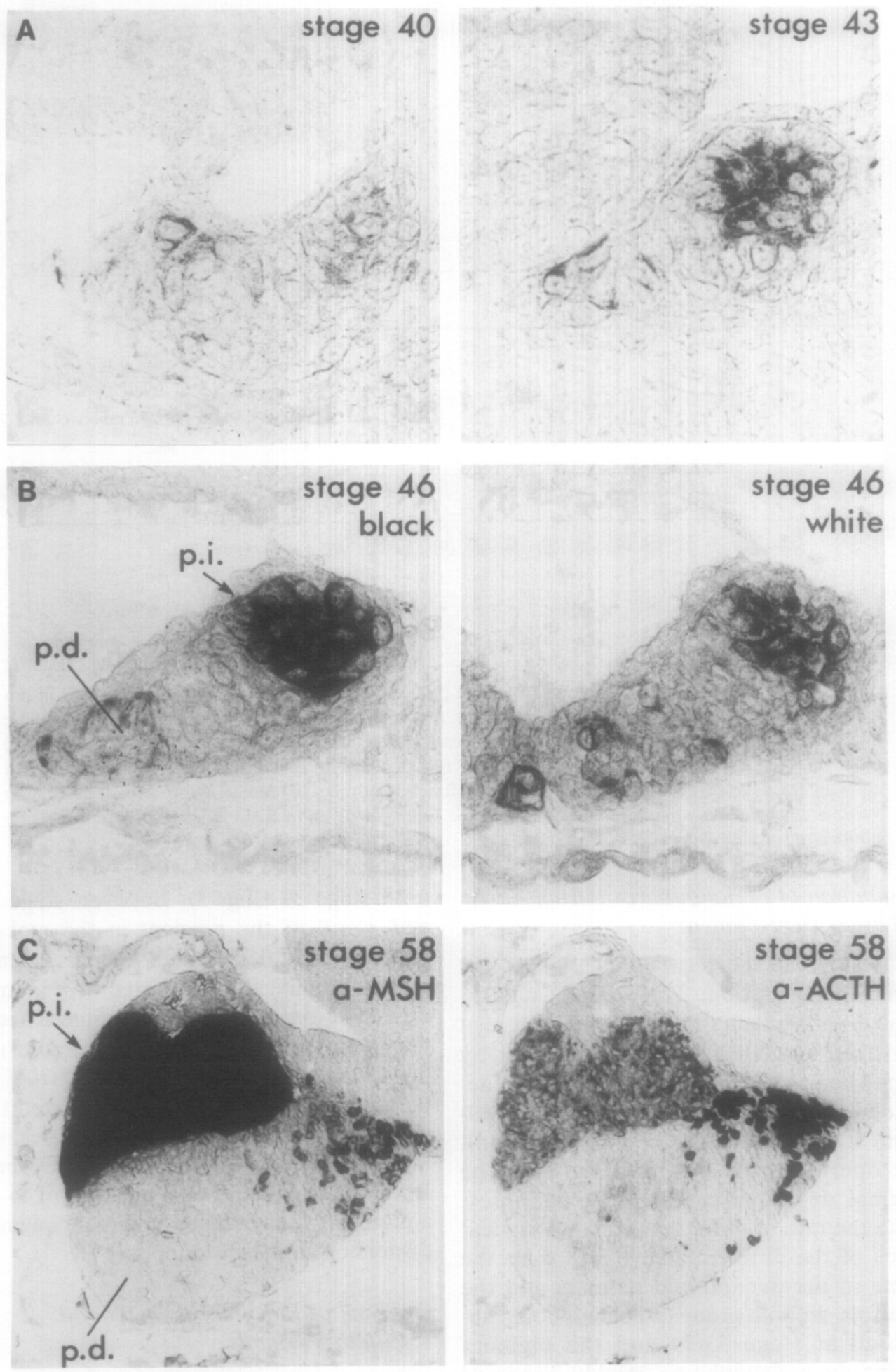

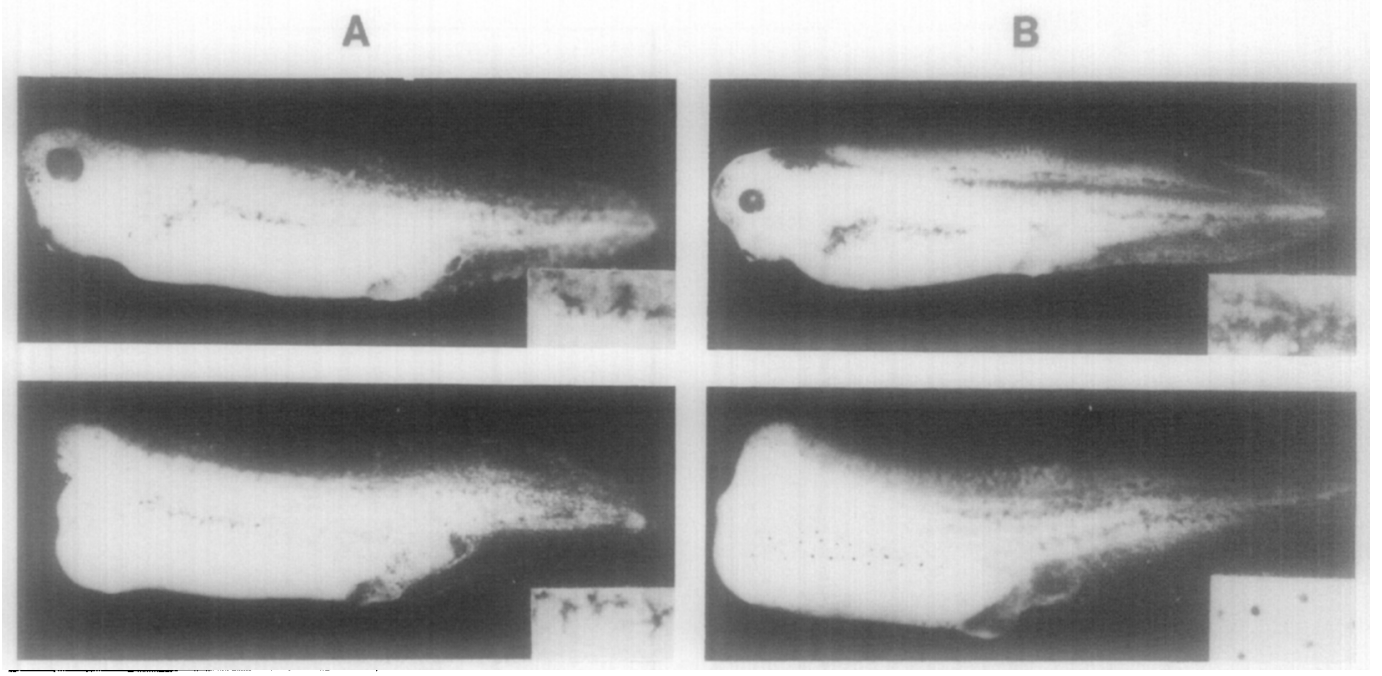

FIG. 3. Effect of decapitation on the appearance of melanophores in tadpoles of $X$. laevis maintained on a black background. (A) Stage 35/36: note fully expanded melanophores in both the control (upper) and decapitated (lower) animal. (B) Stage 41: note aggregation of pigment in decapitated animal only (lower). An enlargement of the melanophores is shown in the lower right corner in each photograph.

ments could not be obtained and the incubations were, therefore, performed with whole pituitary glands. HPLC profiles of newly synthesized peptides obtained from such incubations are presented in Fig. 4. These profiles, in particular at the later stages of development, are essentially the same as those obtained from the pars intermedia of adult animals, although occasionally additional peaks were found, e.g., peak A (Fig. 5). Since it was possible to dissect out intact pars distalis of larvae, separate pulse-chase incubations with this tissue were carried out. In this manner we could assess whether any of the peptides represented in the HPLC profile from whole pituitary glands were derived from the pars distalis. It could be shown that of the HPLC profiles obtained from whole pitu- itary glands only peak $A$ was also found in the chromatogram of the pars distalis. We conclude that products I, II, IV, V, VII, and VIII (Fig. 4) are newly synthesized products from the pars intermedia. In adults these products have been identified: I, a $\gamma_{3}$-MSH-like peptide; II, des- $N$ - $\alpha$ acetyl- $\alpha-\mathrm{MSH}$; IV, two coeluting peptides, $\alpha-\mathrm{MSH}$, and CLIP-1; V, CLIP-2; VII, endorphin-1; VIII, endorphin-2 (Martens et al., 1980, 1982a-c).

The earliest stage in which biosynthetic activity could be analyzed was stage $47 / 48$. Despite the fact that in this experiment 20 lobes were incubated, the HPLC profiles were very low. Most of the peptides listed above as I-VIII were present, but there was a predominance of newly synthesized melanotropins (products I and II), while the

FIG, 2. (A) Immunocytochemical localization of $\alpha-M S H$ in the pituitary gland of young $X$. laevis larvae. Both animals were raised on a black background. Note the dramatic increase in staining intensity between the stage 40 and stage 43 animal. $(140 \times$.) (B) An example of immunocytochemical localization of $\alpha-\mathrm{MSH}$ in $X$. laevis tadpoles raised on a black or white background. (120 $\times$.) (C) Comparison of immunocytochemical localization using antisera to $\alpha$-MSH and ACTH. Tadpoles were raised on a black background. $(66 \times$.) p.i., pars intermedia; p.d., pars distalis. 

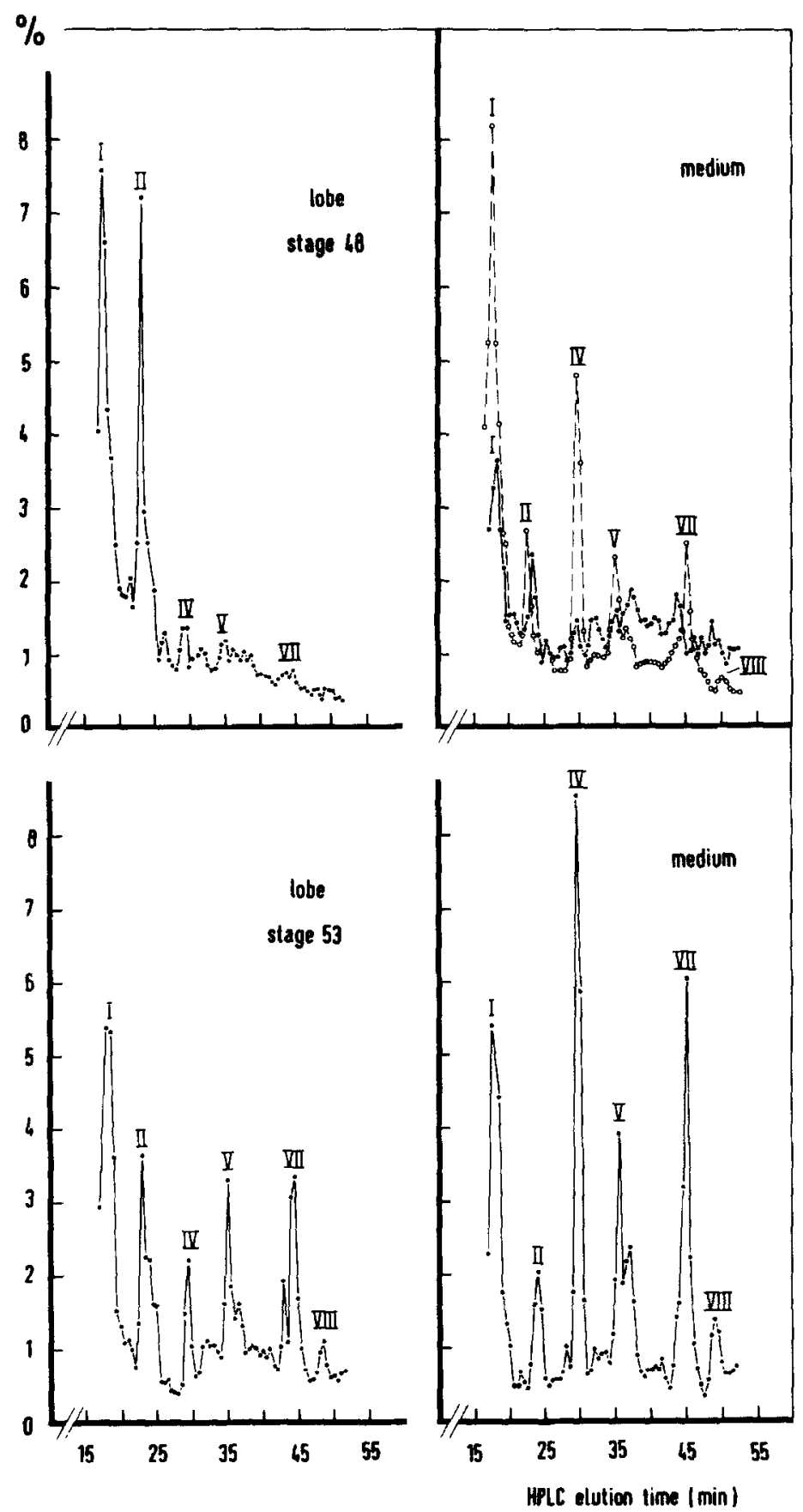

FIG. 4. High-performance liquid chromatographic analysis of in vitro synthesis and release of POMCderived peptides of black-adapted $X$. laevis tadpoles. In the case of larval stages 48,53 , and 58 , whole pituitary glands were incubated; for the adults, neurointermediate lobes were used. Tissue was incubated in the presence of $\left[{ }^{3} \mathrm{H}\right] \mathrm{ly}$ sine and $\left[{ }^{3} \mathrm{H}\right]$ phenylalanine for $2 \mathrm{hr}$, followed by a 2 -hr chase incubation. For each chromatogram the amount of radioactivity in each fraction is expressed as a percentage of the total elution. For each experiment the tissue profile (lobe) is shown on the left and that of the corresponding incubation medium on the right. Identity of products: I, $\gamma_{3}$-MSH-like peptide; II, des- $N$ - $\alpha$-acetyl- $\alpha$-MSH; IV, $\alpha$-MSH, CLIP-1; V, CLIP-2; VI, identity unknown; VII, endorphin-1, VIII, endorphin-2. Elution gradient (\% secondary solvent, B) is given in the lower right figure. Dashed line in the profile of the medium for stage 48 gives the results after incubation in the presence of $6 \mathrm{~m} M$ 8-Br-cAMP. 


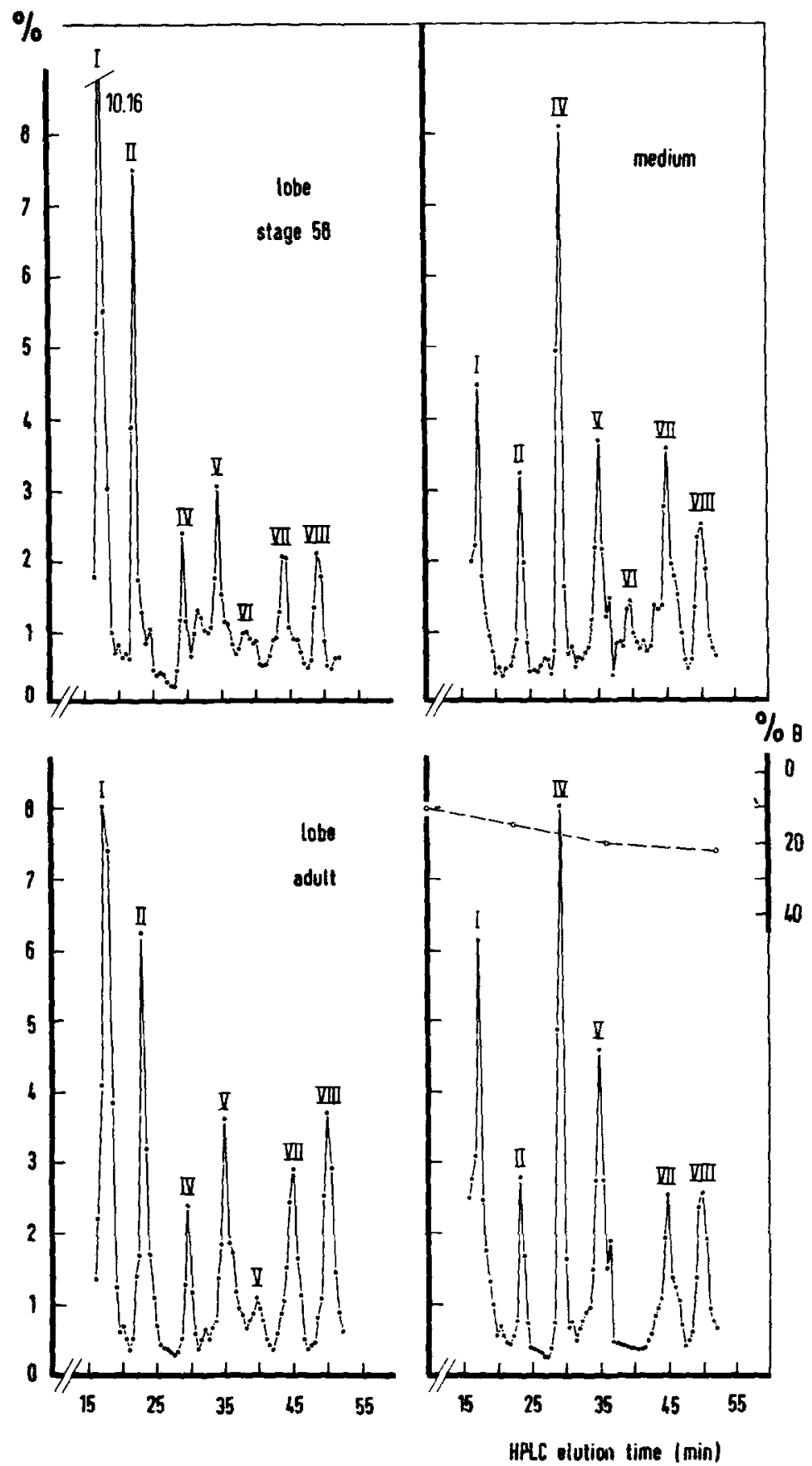

FIG. 4-Continued.

presence of endorphin-2 (peak VIII) was questionable. Incorporation of radioactive amino acids in the pituitary increased considerably with increasing size and devel- opmental stage of the animals. At stage 53, endorphin-2 still represented a small fraction of the newly synthesized products, but by stage 58 its contribution to the HPLC 


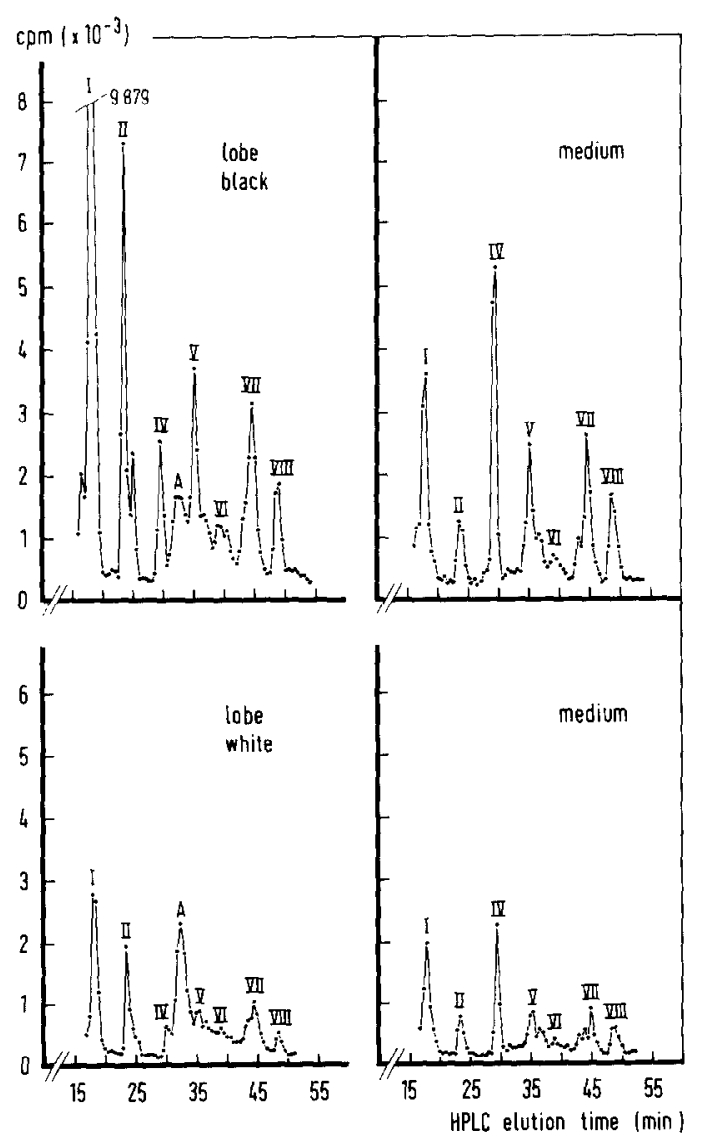

FIG. 5. Comparison of peptide synthesis and release by pituitary glands of black- and white-adapted tadpoles of stage 54. High-performance liquid chromatographic analysis of lobes and media after a 2 -hr pulse incubation in the presence of $\left[{ }^{3} \mathrm{H}\right]$ lysine and $\left[{ }^{3} \mathrm{H}\right]$ phenylalanine, followed by a $2-\mathrm{hr}$ chase incubation. For peak identification see Fig. 4; product A was shown to be a product from the pars distalis.

profile had reached almost the level found in adults (Fig. 4). At metamorphosis the incorporation of labeled amino acids in the pituitary gland was approximately $15 \%$ of that incorporated by adult lobes.

Release of products into the incubation medium was observed in animals older than stage 50 and the HPLC profiles of these media were very similar to those obtained from the lobes, with two exceptions. Relative to the lobe profile, the medium contained little product II, while the reverse was true with regard to product IV. In the youngest stage investigated, namely, stage 48 , the over-all incorporation was so low that analysis of the medium was very difficult; only products I and II were clearly distinguishable. To further analyze release in this early stage, a separate experiment was conducted whereby 8-bromo-3',5'cyclic adenosine monophosphate $(8-\mathrm{Br}$ cAMP; Sigma, St. Louis, Mo.) was added to stimulate secretion. In this case, with the exception of product VIII, the complete profile of newly synthesized peptides was found in the medium. Incorporation of radioactive amino acids into pituitary glands of white-adapted larvae was always very low when compared to that in blackadapted tadpoles (Fig. 5).

\section{DISCUSSION}

Our observations show that in larvae of $X$. laevis the dermal melanophores first appear at stage $33 / 34$. The melanin in these cells was initially in a perinuclear position, but quickly dispersed throughout the cytoplasm and its extensions. This dispersed stage of pigment was seen both in tadpoles on a white background and in tadpoles on a black background. Between stages 39 and 41 the animals developed the capacity to adapt to a white background. These observations confirm those of Bagnara (1963) and Terlou and Van Straaten (1973). Bagnara has suggested that the dispersed condition of the melanophores during stages 33 through 39 is due to uninhibited release of MSH from the pituitary gland. Our data do not support this hypothesis. From stages 33 to 37 we could not demonstrate immunocytochemically the presence of MSH or any other POMC-related peptides in the pars intermedia. While it has been argued (e.g., Nyholm and Doerr-Schott, 1977) that the absence of MSH could be the consequence of the immediate release of the hormone following its biosynthesis, we would like to point out that we experienced no difficulty in demonstrating immunoreactive 
MSH in the pars intermedia of blackadapted larvae of later stages. This indicates that the sensitivity of our immunocytochemical technique was not a limiting factor in demonstrating the presence of melanotropins in actively secreting lobes. We would thus conclude that the lack of immunocytochemically demonstrable melanotropins in these young larvae is due to the fact that the pars intermedia is not yet producing such peptides. In our animals the adenohypophyseal primordium did not reach the position underneath the infundibulum until stage $38 / 39$. Pehlemann and others (for review, see Pehlemann, 1962) have performed experiments with pituitary primordia in a number of amphibians, including Xenopus, and established that contact of the adenohypophyseal primordium with the infundibulum is a requirement for differentiation of the tissue to produce melanotropins. The results of our decapitation experiments also indicate that melanin dispersion in stages 33 to 39 is not due to melanotropins of pituitary origin. Repcated analysis of decapitated animals clearly showed that the pigment in their melanophores remained dispersed between stages 33 and 39. Altogether, we conclude that pituitary production of melanotropins begins at about stage 39. At this stage intact larvae acquire the ability to adapt to a black background, while decapitated larvae aggregate their pigment.

The absence of pituitary control of melanophores in tadpoles prior to stage 39 raises an intriguing question. Is there a melanotropin of extrapituitary origin? We observed that, in general, dorsal melanophores of animals on white background showed pigment aggregation earlier than the more ventrally located melanophores. This corresponded with the disappearance of yolk granules which led us to consider that in early stages of development melanotropic activity emanates from the yolk material. A preliminary experiment indeed demonstrated that a crude extract from
Xenopus eggs causes melanin dispersion in melanophores of incubated tails of young larvae. We are presently attempting to isolate and characterize this factor. The temporary aggregation of pigment occasionally noted in tadpoles on a black background at stage $39 / 40$ indicates that in these cases the yolk factor disappeared before the pars intermedia was capable of assuming the control of melanin dispersion.

Although our immunocytochemical analysis revealed the presence of POMC-related peptides in the pars intermedia, this technique does not permit complete product identification. Because of the close structural relationships of some of the terminal products, cross-reactivity is likely to occur. Moreover, cross-reactivity with intermediate products in the biosynthesis of these peptides or with the prohormone itself cannot be ruled out. The results of biochemical analysis showed that in the tadpoles from stage 51 onward the profiles of newly synthesized peptides were very similar to those of adults. On the basis of the identification of newly synthesized peptides in adults by Martens et al. (1982a), we propose that terminal products in larval Xenopus are a $\gamma_{3}$-MSH-like peptide, des- $N$ $\alpha$-acetyl- $\alpha$-MSH, $\alpha$-MSH, two CLIPs, and two endorphin-like peptides. In larvae, adaptation to a black background induced higher rates of biosynthesis, an observation also reported for adults (Whur and Weatherhead, 1971; Jenks et al., 1977; Loh and Gainer, 1977). From stage 51 onward, and including the adult stage, peak II, representing des- $N$ - $\alpha$-acetyl- $\alpha$-MSH, constituted a major tissue product, but was very low in the medium. The opposite was found with respect to peak IV. In the lobe, peak IV represents CLIP-1, while in the medium this peak represents the coeluting peptides CLIP-1 and $\alpha$-MSH (Martens et al., 1982c). In aduits it has been demonstrated that the predominance of des- $N$ - $\alpha$-acetyl- $\alpha$-MSH in the tissue and the occurrence of $\alpha$-MSH primarily in the medium is because the ace- 
tylation of des- $N$ - $\alpha$-acetyl- $\alpha$-MSH to yield MSH is closely related to the release process (Martens et al., 1981a). Although in the present study we did not separately determine the two peptides that are probably coeluting as peak IV, in our opinion the similarity between our findings in the larvae and those in the adults indicates that, in larvae of stage 51 and older, acetylation of newly synthesized des- $N$ - $\alpha$-acetyl- $\alpha$-MSH is also linked to the release process.

It was hoped that with the biosynthetic studies we would be able to follow the development of the various biosynthetic processes necessary for pars intermedia function such as the capacity to produce POMC, the acquisition of the enzymatic system for processing of the prohormone, and, finally, the ability to release the terminal products. Unfortunately, dissection of pituitary glands for such studies in very young larvae was very difficult. In animals of stage 48 , the earliest stage which permitted biochemical analysis, several deviations from the results obtained with later larvae or adult pars intermedia were noted. The amounts of melanotropins synthesized by the glands of animals of stage 48 were extremely high, relative to the other POMC-related peptides. This might suggest a different manner of processing POMC in these young larvae. It was clear from the results that these lobes were capable of releasing newly synthesized melanotropins. The fact that the des-acetyl form of $\alpha$-MSH was the major form of the peptide released spontaneously into the medium, indicates that the acetylation mechanism may be less active in these early larvae. Apparently cAMP is able to activate this mechanism, indicated by the fact that peak IV was a major peak in the medium following CAMP treatment. The adult pars intermedia produces two sequentially different POMCs, one difference being located in the endorphin region of the prohormones (Martens $e t$ al., 1982c); one of these prohormones gives rise to endorphin-1 (product VII) and the other to endorphin-2 (product VIII). The total absence of endorphin-2 in the profiles at stage 48 suggests that in this early stage only one of the prohormones is synthesized and/or processed. The contribution of endorphin-2 to the profiles gradually increased in later stages such that by stage 57 the adult profile was obtained.

In conclusion, our results in combination with those of others show that stage $39 / 40$ is a critical stage in the development of a number of different components of the neuroendocrine system which enable Xenopus tadpoles to adapt to their background. At about this stage there is a loss of a melanotropic factor, probably emanating from the yolk material. In this critical period the adenohypophyseal primordium reaches the infundibulum and the pars intermedia quickly differentiates to produce POMC-related peptides. Consequently, the animals acquire the ability to regulate the pigment in their dermal melanophores. The first innervation of the pars intermedia by aminergic neurons apparently also takes place at about stage $39 / 40$ (Terlou and Van Straaten, 1973). Our results show that a dopamine agonist acts as an effective inhibitor of $\mathrm{MSH}$ release during this period. The remarkable coordination in the development of the various components of the neuroendocrine system for background adaptation if further supported by a recent study by Holt and Harris (1983). They demonstrated that retinal projections in Xenopus larvae reach the optic tectum and are organized topographically in their final form at stage 39/40. Thus, both the ability to produce the melanotropins and the development of the regulatory mechanisms are established during stage $39 / 40$ and impart to the tadpoles their capacity for background adaptation.

\section{ACKNOWLEDGMENTS}

We thank Mr. P. M. J. M. Cruijsen and Mr. R. J. C. Engels for their technical assistance, Mr. Th. Oor for 
the illustrations, and Mrs. E. M. Jansen-Hoorweg for typing the manuscript.

\section{REFERENCES}

Atwell, W. J. (1919). On the nature of pigmentation changes following hypophysectomy in the frog larva. Science (Washington DC) 49, 48-50.

Bagnara, J. T. (1963). The pineal and the body lightening reaction of larval amphibians. Gen. Comp. Endocrinol. 3, 86-100.

Etkin, W. (1941). The first appearance of functional activity in the pars intermedia in the frog, Xenopus. Proc. Soc. Exp. Biol. Med. 47, 425-428.

Hogben, L., and Slome, D. (1931). The pigmentary effector system: VI. The dual character of endocrine coordination in amphibian color change. Proc. Roy. Soc. London Ser. B. 108, 10-53.

Holt, C. E., and Harris, W. A. (1983). Order in the initial retinotectal map in Xenopus: A new technique for labelling growing nerve fibres. Nature (London) 301, 150-152.

Jenks, B. G. (1977). Control of MSH synthesis and release in the aquatic load, Xenopus laevis. In "Frontiers in Hormone Research" (Van Wimezsma Greidanus, Ed.), Vol. 4, pp. 63-65. Karger, Basel.

Jenks, B. G., van Overbeeke, A. P., and McStay, B. F. (1977). Synthesis, storage, and release of MSH in the pars intermedia of the pituilary gland of Xenopus laevis during background adaptation. Canad. J. Zool. 55, 922-927.

Jenks, B. G., and van Overbeeke, A. P. (1980). Biosynthesis and release of neurointermediate lobe peptides in the aquatic toad, Xenopus laevis, adapted to a black background. Comp. Biochem. Physiol. C 66, 71-76.

Lerner, A. B., Shizume, K., and Bunding, I. (1954). The mechanism of endocrine control of melanin pigmentation. J. Clin. Endocrinol. Metab. 14, 1463-1490.

Loh, Y. P., and Gainer, H. (1977). Biosynthesis, processing and control of release of melanotropic peptides in the neurointermediate lobe of Xenopus laevis. J. Gen. Physiol. 70, 37-58.

Martens, G. J. M., Jenks, B. G., and van Overbeeke, A. P. (1980). Analysis of peptide biosynthesis in the neurointermediate lobe of Xenopus laevis using high performance liquid chromatography: Occurrence of small bioactive products. Comp. Biochem. Physiol. B 67, 493-497.

Martens, G. J. M., Jenks, B. G., and van Overbeeke, A. P. (1981a), $N$ - $\alpha$-acetylation is linked to $\alpha$-MSH release from pars intermedia of the amphibian pituitary gland. Nature (London) 294, 558-560.

Martens, G. J. M., Jenks, B. G., and van Overbeeke, A. P. (1981b). Microsuperfusion of neurointermediate lobes of Xenopus laevis: Concomitant and coordinately controlled release of newly synthesized peptides. Comp. Biochem. Physiol. C $69,75-82$.

Martens, G. J. M., Jenks, B. G., and van Overbeeke, A. P. (1982a). Biosynthesis of pairs of peptides related to melanotropin, corticotropin and endorphin in the pars intermedia of the amphibian pituitary gland. Eur. J. Biochem. 122, 1-10.

Martens, G. J. M., Jenks, B. G., and van Overbecke, A. P. (1982b). Biosynthesis of a $\gamma_{3}$-melanotropinlike peptide in the pars intermedia of the amphibian pituitary gland. Eur. J. Biochem. 126, 23-28.

Martens, G. J. M., Biermans, P. J., Jenks, B. G., and van Overbeeke, A. P. (1982c). Biosynthesis of two structurally different pro-opiomelanocortins in the pars intermedia of the amphibian pituitary gland. Eur. J. Biochern. 126, 17-22.

Martens, G. J. M., Soeterik, F., Jenks, B. G., and van Overbeeke, A. P. (1983). In vivo biosynthesis of melanotropins and related peptides in the pars intermedia of Xenopus laevis. Gen. Comp. Endocrinol. 49, 73-80.

Nieuwkoop, P.D., and Faber, J. (1967). "Normal table of Xenopus laevis (Daudin)." North-Holland, Amsterdam.

Nyholm, E. 1., and Doerr-Schott, J. (1977). Developmental immunohistology of melanotrophs in Xenopus laevis tadpoles. Cell Tissue Res. 180, 231-239.

Pehlemann, F. W. (1962). Untersuchungen zur Determination und Differenzierung der Hypophyse bei Anuren. Roux. Arch. Entwicklungsmech. Org. 153, 551-602.

Sternberger, L. A. (1979). "Immunocytochemistry," 2nd ed. Wiley, New York.

Swingle, W. W. (1921). The relation of the pars intermedia of the hypophysis to pigmentation changes in anuran larvae. J. Exp. Zool. 34, 119-141.

Terlou, M., Goos, H. J. Th., and van Oordt, P. G. W. J. (1974). Hypothalamic regulation of pars intermedia activity in amphibians. In Fortschritte der Zoologie"' (M. Lindauer, Ed.), Vol. 22, pp. 117-134. Verlag, Stuttgart.

Terlou, M., and van Straaten, H. W. M. (1973). The development of a hypothalamic monoaminergic system for the regulation of the pars intermedia activity in Xenopus laevis. Z. Zellforsch. 143, 229-238.

Waring, H. (1963). "Color Change Mechanisms of Cold-Blooded Vertebrates." Academic Press, New York.

Whur, P., and Weatherhead, B. (1971). Rates of incorporation of ${ }^{3} \mathrm{H}$-leucine into protein of the pars intermedia of the pituitary in the amphibian Xen. opus laevis after change of background color. $J$. Endocrinol. 51, 521-532. 